\title{
VARIABILITY OF THE PULMONARY VASCULAR RESPONSE TO HYPOXIA AND RELATION TO GAS EXCHANGE IN DOGS*
}

\author{
James B. Forrest and Angelica Fargas-Babjak
}

IN 1904, the French physiologist Plumier ${ }^{1}$ provided the first documented evidence that decreased inspired oxygen caused pulmonary hypertension. Since then, numerous workers have studied the effect of acute hypoxia on pulmonary vascular resistance $e^{2-6}$ and it is now well established that it is the alveolar oxygen tension and not that of the systemic arterial blood which is the main determinant of the pulmonary vascular pressor response to hypoxia. ${ }^{7-10}$ On the other hand, the level of arterial oxygen saturation is largely determined by the relationship between ventilation and perfusion 11 which is in turn determined by the pulmonary vascular response to local hypoxia. While this response is present in all species so far tested, ${ }^{9}$ the magnitude of the increase in pulmonary vascular resistance (PVR) for a given level of alveolar hypoxia varies greatly between species. ${ }^{12}$ Further, in single species, the hypoxic pressor response shows considerable variation when related to arterial oxygen tensions, as for instance in the published reports for the dog. $3,6,13-17$

Since the role of the PVR response to hypoxia would seem to be to minimize arterial oxygen desaturation, any individual variation in the response could indicate differences in the adaptation of the gas exchange apparatus of the lungs to a given hypoxic stimulus. The purpose of this study was to determine whether the PVR response to hypoxia is uniquely related to arterial oxygen saturation in individual animals. Mechanically ventilated anaesthetized dogs were used so that the PVR response could be studied uninfluenced by changes in ventilation.

\section{Materials and Methods}

Twelve adult mongrel dogs (weight range

James B. Forrest, M.B., Ch.B., Ph.D., F.F.A.R.C.S., Associate Professor, and Angelica Fargas-Babjak, M.D., Resident in Anaesthe sia. Departments of Anaesthesia and Medicine, McMaster University Health Sciences Centre, Hamilton, Ontario, Canada, L8S 4J9.

*Supported by the Canadian Medical Research Council, Grant \# MA 5880. Presented in part at the Canadian Anaesthetists' Society Meeting, June 20-23, 1977.

Canad, Anaesth. Soc. J., vol. 25, no. $\dot{6}$, November 1978
$17.25-32.2 \mathrm{~kg}$ ) were anaesthetized with intravenous pentobarbitone (dose $30 \mathrm{mg} / \mathrm{kg}$ ) and intubated with a cuffed tracheal tube. Muscle paralysis was induced with pancuronium bromide (dose $0.06 \mathrm{mg} / \mathrm{kg}$ ) and mechanical ventilation started with intermittent positive pressure from a Harvard respirator. Tidal volume and respiratory frequency were set using the Radford nomogram and maintained at constant levels throughout the experiment. Supplemental doses of anaesthetic and muscle relaxant were given as required.

Catheters were placed in the left femoral artery for blood pressure monitoring, the right femoral artery for arterial blood gas sampling, and in the left femoral vein for administration of drugs and for venous sampling of haemoglobin and haematocrit. A number 7 triple-lumen SwanGanz catheter was inserted through the right femoral vein into the pulmonary artery for continuous measurement of pulmonary artery pressure (Ppa), and intermittent measurement of pulmonary wedge pressure (Pwp). Cardiac output $(\dot{Q})$ was measured by the thermodilution method using an Edwards cardiac output computer (9510-A). Samples of pulmonary arterial blood were obtained for estimation of mixed venous blood gases and $\mathrm{pH}$.

The electrocardiogram was recorded. Rectal temperature was measured by thermistor probe (Yellow Springs Lab. Inc.), airway pressure, (AWP) by a needle inserted into the tracheal tube, and continuous breath to breath oxygen and carbon dioxide concentrations by Beckman OM-1I oxygen analyser and LB-2 gas analyser. Mixed expired carbon dioxide concentrations were measured intermittently using a mixing box inserted in the expiratory line. All pressures were measured by Statham transducers (P37b) and together with the electrocardiogram and respired gas concentrations were recorded on HewlettPackard (HP 2201) and Beckman Dynograph (Type R411) pen recorders. A thermostatically controlled warming blanket prevented cooling during the experiment.

Air was used as the inspired gas initially in all experiments and then supplemented with oxygen if required to achieve more than 98 per cent arte- 
rial oxygen saturation. Thereafter the same airoxygen mixture was used in any one animal during recovery periods. The mean control inspired oxygen concentration was 28 per cent. This is subsequently referred to as normoxia in so far as arterial blood was fully saturated in the control and recovery periods. Hypoxia was induced by switching to a mixture of oxygen in nitrogen to give inspired oxygen concentrations of $8,11,16$, or 20 per cent.

After an initial control period lasting 60 minutes, during which baseline values of all parameters were obtained by serial estimation, the animals were subjected to a five-minute period of hypoxia followed by a 30-minute recovery period. Five minutes of hypoxia in each case was sufficient time for all measured parameters to achieve equilibrium. Each animal was exposed to the five levels of inspired oxygen during any one experiment and each experiment was repeated at least once in 9 of the 12 dogs. In the remaining three dogs, up to three levels of $\mathrm{Fl}_{\mathrm{O}_{2}}$ were repeated (cf. $(n-1)$ in Table II). The order in which the various levels of hypoxia were administered was varied between animals to allow comparison of the effects of repeated exposure.

Mixed venous and arterial blood gases and $\mathrm{pH}$ measurements were made in an Instrumentation Laboratory $\mathrm{pH} / \mathrm{gas}$ analyser by the microelectrode technique. Samples were collected anaerobically in heparinized glass syringes. Calibration by tonometry was done throughout each experiment at regular intervals. Oxygen saturation ( $\mathrm{s}$ ) was calculated using the measured $\mathrm{PO}_{2}$ corrected for temperature and $\mathrm{pH}$ from the Rossing and Cain ${ }^{18}$ equation for dog blood thus: $\log (\mathrm{s} / \mathrm{l}-\mathrm{s})=2.5198 \log \mathrm{Po}_{2}+1.1804$ ( $\left.\mathrm{pH}-7.0\right)-$ $0.0472-2.3621$. Pulmonary vascular resistance (PVR) was calculated from PVR = (Ppa Pwp) $/ \dot{Q}$ expressed as $\mathrm{mmHg} l^{-1} \mathrm{~min}$. Additional calculated parameters were dead space/tidal volume ratio (Vo/Vr), pulmonary shunt fraction (Q́s/Q⿱t) and the alveolar to arterial oxygen gradient $\mathrm{P}(\mathrm{A}-\mathrm{a}) \mathrm{O}_{2}$.

\section{Statistical Analysis}

Data were analysed by $\$$ tudent's paired t test. Linear regression analysis was done by analysis of variance of paired values. In the case of PVR and $\mathrm{Ppa}$ against $\mathrm{Pa}_{\mathrm{O}_{2}}$, these included quadratic regression analysis. Statistical significance was taken as $\mathrm{P}=0.05$ or less. Highly significant refers to values where $\mathrm{P}=0.01$ or less.

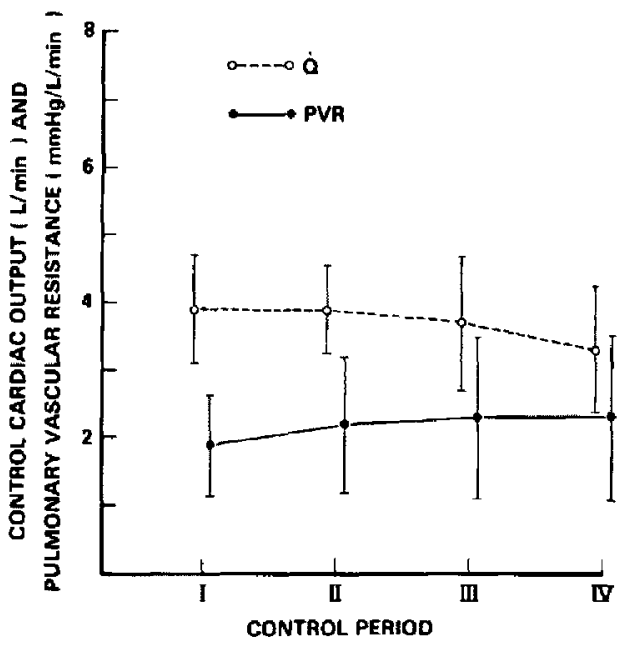

Figure I. The mean values \pm I SDare shown for all dogs for cardiac output (open circles) and for pulmonary vascular resistance (closed circles) for each control period between hypoxic episodes.

\section{RESULTS}

\section{Controls: effect of repeated exposure}

There was a small (12 per cent) decrease in the mean control $\dot{Q}$ after repeated hypoxia while mean control Ppa increased by about three per cent; thus PVR increased with successive hypoxic episodes by about 20 per cent after the fourth episode compared to initial values, but as with $\dot{Q}$ this was not significant (Figure 1). Individual animals in each case followed the same trend. No change was found for Pwp, AWP, heart rate or mean systemic blood pressure, during these control periods.

\section{Group mean values}

The mean values of all control periods for the 12 dogs are given in Table I and compared to the pooled mean hypoxic values. Hypoxia in all cases increased Ppa to a mean for the group which was 43 per cent above control values. Similarly, PVR was increased by about 56 per cent, while $Q$ was decreased by only two per cent. There was a small increase in systemic arterial BP of eight per cent in the hypoxic group. Arterial $\mathrm{pH}$ increased from a mean control value of 7.38 to $7.41 \mathrm{(H}^{+}$ decrease from 41.69 to $38.9 \mathrm{nmol} \mathrm{I}^{-1}$ ) while $\mathrm{Pa}_{\mathrm{CO}_{2}}$ was reduced from 36.96 to $34.94 \mathrm{~mm} \mathrm{Hg}$ (4.92 to $4.65 \mathrm{kPa}$ ), with hypoxia, while mean values for $\mathrm{Pa}_{2}$ were 98.2 and $45.65 \mathrm{~mm} \mathrm{Hg}$ (13.06 and 6.07 kPa) respectively. The slightly lower $\mathrm{Pa}_{\mathrm{CO}_{2}}$ was 
TABLE I

\begin{tabular}{|c|c|c|c|c|}
\hline Variable & & Control \pm 1 SD & Hypoxia \pm 1 SD & $\mathbf{P}$ \\
\hline Pulmonary vascular resistance & $\begin{array}{l}\mathrm{kPa} \cdot \mathrm{l}^{-1} \cdot \min \\
\left(\mathrm{mm} \mathrm{Hg} \cdot \mathrm{l}^{-1} \cdot \mathrm{min}\right)\end{array}$ & $\begin{array}{c}0.29 \pm 0.03 \\
(2.15 \pm 0.21)\end{array}$ & $\begin{array}{c}0.45 \pm 0.21 \\
(3.35 \pm 1.59)\end{array}$ & 0.0005 \\
\hline Pulmonary artery pressure & $\begin{array}{l}\mathrm{kPa} \\
(\mathrm{mm} \mathrm{Hg})\end{array}$ & $\begin{array}{c}1.69 \pm 0.43 \\
(12.70 \pm 3.25)\end{array}$ & $\begin{array}{c}2.42 \pm 0.83 \\
(18.16 \pm 6.27)\end{array}$ & 0.0005 \\
\hline Cardiac output & $1 \cdot \min ^{-1}$ & $3.90 \pm 0.64$ & $3.83 \pm 1.01$ & N.S. \\
\hline Mean arterial pressure & $\begin{array}{l}\mathbf{k P a} \\
(\mathrm{mm} \mathrm{Hg})\end{array}$ & $\begin{array}{c}20.02 \pm 3.43 \\
(150.55 \pm 25.78)\end{array}$ & $\begin{array}{c}21.57 \pm 3.87 \\
(162.17 \pm 29.10)\end{array}$ & N.S. \\
\hline Mean airway pressure & $\begin{array}{l}\mathrm{kPa} \\
(\mathrm{mm} \mathrm{Hg})\end{array}$ & $\begin{array}{c}0.52 \pm 0.16 \\
(3.91 \pm 1.24)\end{array}$ & $\begin{array}{l}0.53 \pm 0.17 \\
(3.99 \pm 1.29)\end{array}$ & NiS. \\
\hline Arterial pH & $\begin{array}{l}\text { nmol. } 1, \mathrm{H}^{+} \\
\text {(pH units) }\end{array}$ & $\begin{array}{l}42.00 \pm 3.00 \\
(7.38 \pm 0.03)\end{array}$ & $\begin{array}{l}39.00 \pm 3.00 \\
(7.41 \pm 0.03)\end{array}$ & N.S. \\
\hline Arterial oxygen tension & $\begin{array}{l}\mathrm{kPa} \\
\text { (torr) }\end{array}$ & $\begin{array}{c}13.06 \pm 1.95 \\
(98.20 \pm 14.63)\end{array}$ & $\begin{array}{c}6.07 \pm 2.39 \\
(45.65 \pm 18.00)\end{array}$ & 0.0005 \\
\hline Arterial carbon dioxide tension & $\begin{array}{l}\mathrm{kPa} \\
\text { (torr) }\end{array}$ & $\begin{array}{c}4.92 \pm 0.50 \\
(36.96 \pm 3.77)\end{array}$ & $\begin{array}{c}4.65 \pm 0.59 \\
(34.95 \pm 4.44)\end{array}$ & N.S. \\
\hline End tidal carbon dioxide & per cent & $5.46 \pm 0.08$ & $5.31 \pm 0.08$ & N.S. \\
\hline Mixed expired carbon dioxide & per cent & $2.66 \pm 0.01$ & $2.60 \pm 0.01$ & N.S. \\
\hline Pulmonary shunt fraction & per cent & $3.51 \pm 0.98$ & $1.09 \pm 0.79$ & 0.0005 \\
\hline Alveolar-arterial oxygen & $\begin{array}{l}\mathbf{k P a} \\
\text { (torr) }\end{array}$ & $\begin{array}{c}7.45 \pm 0.82 \\
(56.04 \pm 6.15)\end{array}$ & $\begin{array}{c}2.13 \pm 1.56 \\
(16.00 \pm 11.76)\end{array}$ & 0.0005 \\
\hline Dead space/tidal volume ratio & & $49.62 \pm 6.65$ & $47.83 \pm 9.28$ & N.S. \\
\hline Hacmatocrit & per cent & $42.96 \pm 5.39$ & $45.77 \pm 5.00$ & N.S. \\
\hline
\end{tabular}

N.S. $=$ not significant where $\mathbf{P}>0.05$.

reflected in a three per cent reduction in end expired fractional carbon dioxide concentrations and a two per cent reduction in mixed expired carbon dioxide. The mean values for shunt fraction (Qs/Qt) showed a large reduction in the hypoxic group of 70 per cent compared to controls, with a similar reduction found for $P(A-a) O_{2}$. No significant change was found for $V_{D} / V_{T}$, AWP or Pwp with hypoxia.

\section{Pulmonary Vascular Resistance}

All animals showed increased Ppa and PVR with hypoxia but the magnitude of these increases varied greatly between animals. Figure 2 shows the individual PVR values plotted against $\mathrm{Pa}_{\mathrm{O}_{2}}$. In all cases, little change occurred in PVR until $\mathrm{Pa}_{\mathrm{O}_{2}}$ was reduced to less than $70 \mathrm{~mm} \mathrm{Hg}$; however, no significant statistical correlations could be found for these curvilinear responses. The rise in PVR and also Ppa was delayed in all cases for one to two minutes after switching to the hypoxic inspired gas mixture and, in general, the shortest delays occurred with the lowest $\mathrm{FI}_{\mathrm{O}_{2}}$ values of 0.08 . The increase in PVR reached a plateau after four minutes in $\$ 2$ hypoxic runs and after three minutes in eight hypoxic runs. In all cases these plateau values of PVR were unchanged after five minutes. All reported hypoxic values refer to measurements done at five minutes.

When PVR was plotted against percent oxygen saturation $\left(\% \mathrm{O}_{2}\right.$ sat.), significant inverse linear relationships were found for all dogs (Figure 3 and Table II). In individual animals these linear PVR $/ \% \mathrm{O}_{2}$ sat, responses were highly reproduceable in each case, with the exception of dog number five, where PVR responses were repeated for only two levels of $\mathrm{FI}_{\mathrm{O}_{2}}$. However, with $\operatorname{dog} 5$ these PVR values at equivalent $\mathrm{F}_{\mathrm{l}_{2}}$ were very nearly identical. On the other hand, comparison between animals clearly shows great variability. The values for slope, intercept, correlation coefficient and significant level are given for each dog in Table II. The slopes of these PVR/\% $\mathrm{O}_{2}$ sat. responses ranged from -0.013 to -0.144 but 83 per cent of these were less than -0.06 and 42 per cent were between -0.04 and -0.06 . Thus it was possible to categorize dogs as (a) low responders having a slope of less than -0.04 ( 41 per cent), (b) medium responders having a slope be- 
TABLE II

\begin{tabular}{|c|c|c|c|c|c|c|c|}
\hline \multicolumn{5}{|c|}{ PVR $/ \% \mathrm{O}_{2}$ sat. } & \multicolumn{2}{|c|}{$\mathrm{Ppa} / \% \mathrm{O}_{2}$ sat. } & $\mathbf{r}$ \\
\hline 1 & 12 & -0.144 & 16.3 & $0.951^{*}$ & -0.561 & 70.7 & $0.952^{*}$ \\
\hline 2 & 10 & -0.019 & 3.5 & $0.964^{*}$ & -0.125 & 27.0 & $0.564 t$ \\
\hline 3 & 8 & -0.057 & 6.7 & $0.842^{*}$ & -0.362 & 45.0 & 0.597 N.S. \\
\hline 4 & 7 & -0.023 & 3.7 & 0.8511 & -0.108 & 22.6 & $0.844 \dagger$ \\
\hline 5 & 6 & -0.019 & 3.7 & $0.815 \ddagger$ & -0.040 & 16.5 & 0.493 N.S. \\
\hline 6 & 7 & -0.044 & 5.8 & $0.948 *$ & -0.091 & 17.6 & $0.849 \ddagger$ \\
\hline 7 & 9 & -0.048 & 5.8 & $0.834^{*}$ & -0.230 & 32.5 & $0.969^{*}$ \\
\hline 8 & 9 & -0.013 & 3.0 & $0.598 t$ & -0.076 & 18.7 & $0.788 \dagger$ \\
\hline 9 & 9 & -0.055 & 8.8 & $0.846 \dagger$ & -0.229 & 38.2 & $0.940^{*}$ \\
\hline 10 & 9 & -0.064 & 8.4 & $0.972^{*}$ & -0.224 & 31.7 & $0.942^{*}$ \\
\hline 11 & 9 & -0.037 & 7.9 & $0.779 t$ & -0.038 & 19.8 & 0.592 N.S. \\
\hline 12 & 9 & -0.056 & 8.2 & $0.845^{*}$ & -0.195 & 33.6 & $0.847^{*}$ \\
\hline
\end{tabular}

$b_{\mathrm{x}}, b_{p}=$ slope, $I=$ intercept, $r=$ correlation coefficient $(Y=b X+I)$.

* = significant at $P=0.001$

$\dagger=$ significant at $\mathbf{P}=0.01$

$\ddagger=$ significant at $\mathbf{P}=0.05$.

$\mathrm{NS}=$ not significant where $\mathrm{P}>0,05$.

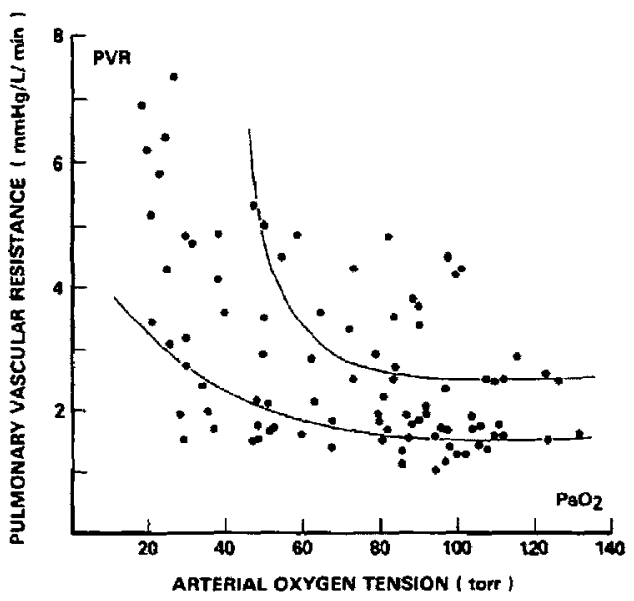

Figure 2. Pulmonary vascular resistance is plotted as mean values for individual runs against arterial oxygen tension. The two curves shown were drawn through the data from two dogs, but in no case were curves statistically significant at the 5 per cent probability level.

tween -0.04 and -0.06 ( 42 per cent), or (c) high responders having a slope greater than $-0.06(17$ per cent). The mean slope for all dogs was -0.048 with a mean correlation coefficient of 0.822 . Similar inverse linear relationships were obtained for Ppa against per cent oxygen saturation but the overall level of significance was lower than for PVR (Table II). The mean slope for $\mathrm{Ppa} / \% \mathrm{O}_{2}$ sat. was -0.190 for a mean correlation coefficient of 0.781 . The predictive value of the slope of Ppa $/ \% \mathrm{O}_{2}$ sat. $\left(\mathrm{b}_{\mathrm{P}}\right)$ for the slope of $\mathrm{PVR} / \% \mathrm{O}_{2}$ sat. $\left(b_{R}\right)$ was tested by an analysis of variance of

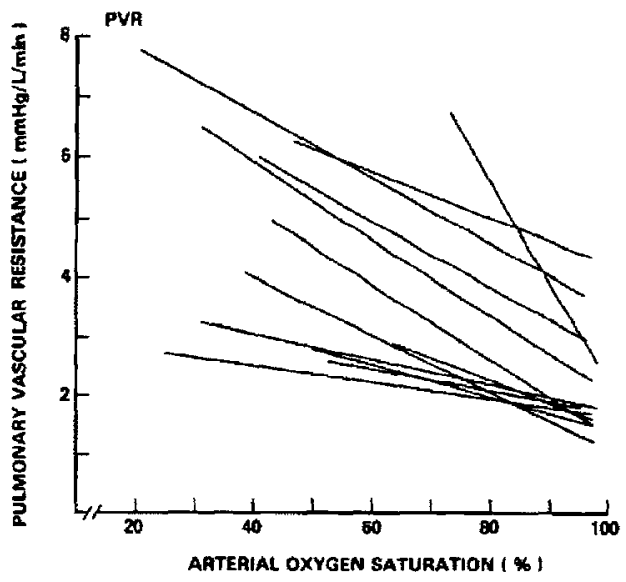

Figure 3. Pulmonary vascular resistance is plotted against arterial oxygen saturation. The regression line for each dog is shown. In ail cases these are highly significant and reproduceable (see text, cf Table II).

paired slope values and was found to be highly significant $(P<0.001)$ such that $b_{R} 0.25 b_{P}-$ 0.001 (where $r=0.909$ ). The high degree of significance of the above relationship was undoubtedly due to the fact that cardiac output and Pwp were relatively unchanged during hypoxic exposures. This result indicates that it was possible with a high predictive accuracy to estimate the change in PVR from the Ppa response. Further the use of a single control and a single hypoxic value of Ppa did not reduce the accuracy of this prediction to any significant extent since individual responses were highly reproduceable. 


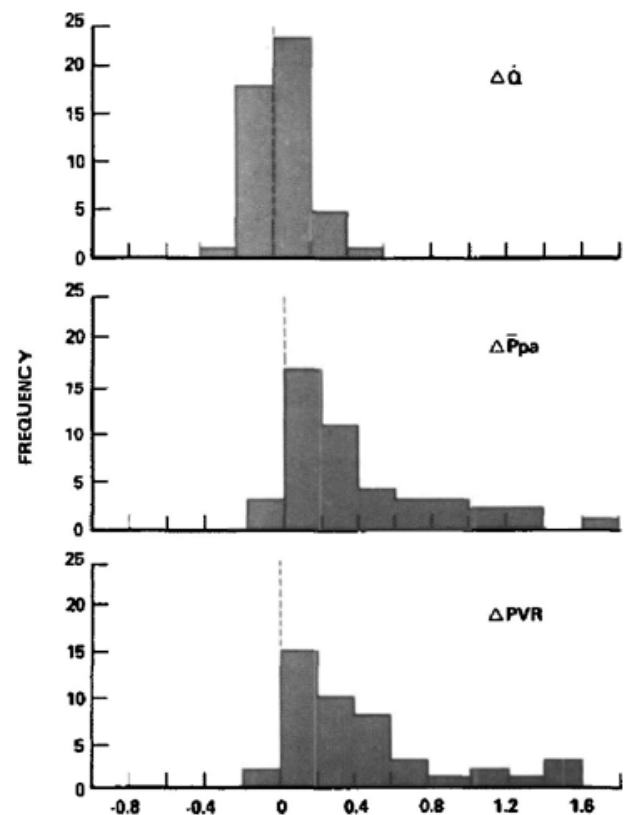

Figure 4. Frequency distributions for change in cardiac output, pulmonary artery pressure and in pulmonary vascular resistance are shown for the pooled data. The units on the abscissa are equivalent and are the fractional changes compared with control.

\section{Sequential hypoxic exposures}

In order to compare the effects of repeated and sequential hypoxic exposures, the values for $\mathrm{Ppa}$ and PVR were expressed as a change compared with the immediately preceding value at normoxia thus: change $=$ (value at 5 min hypoxia control value)/control value. In both cases highly significant and reproduceable inverse linear relationships were again found for all dogs. The slopes of these were only slightly lower than the slope values shown in Table II. In general the correlation coefficients for these slopes were also slightly lower, but none of these differences between the values calculated as change compared to control and the absolute values were significantly different at the one per cent probability level. Thus the PVR and Ppa responses which were found were not significantly altered by the number or the sequence of hypoxic exposures.

\section{Frequency distribution of PVR, $\dot{Q}$ and $P p a$ change}

Since PVR is a calculated parameter and depends on the net change of three variables (Ppa, $P w p$ and $\dot{Q}$ ), the relative influence of each of these during each of the 60 hypoxic exposures has been

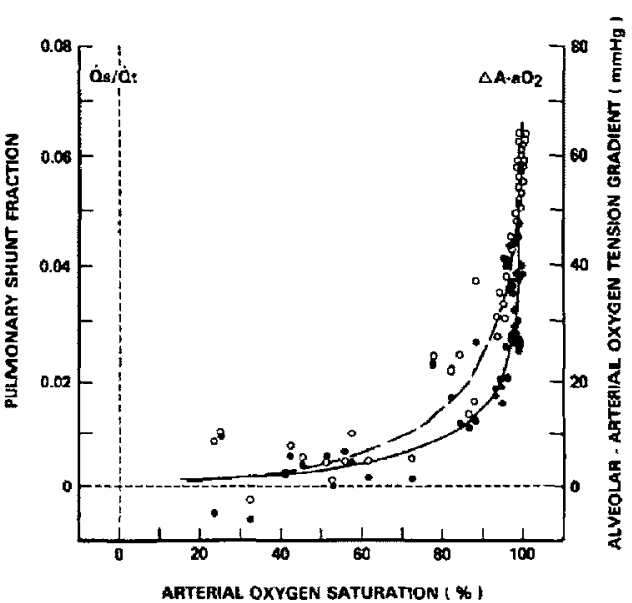

Flgure 5. Pulmonary shunt fraction (closed circles) and alveolar to arterial oxygen gradient (open circles) are plotted against arterial oxygen saturation as mean values for individual runs. The solid curve is drawn through the Qs/Qt values while the broken curve is drawn through the $P(A-a)_{0_{2}}$ values.

analysed. Figure 4 shows the resulting frequency distributions for change in PVR, $\dot{Q}$ and Ppa. The change in Pwp has been omitted since this was unaltered by hypoxia. Clearly the change in Ppa accounts for almost all the change in PVR as seen by the close similarity of the lower two histograms and demonstrates the high degree of predictability of the slope $b_{R}$ from $b_{P}$ described above. The two negative values of change in PVR were obtained from one run in each of two dogs with severe hypoxia $\left(\mathrm{FI}_{\mathrm{O}_{2}}=0.08\right)$.

\section{Pulmonary shunt flow and alveolarlarterial oxygen difference}

There was little variation in $\dot{\mathrm{Q}} \mathrm{s} / \dot{\mathrm{Q}} \mathrm{t}$ or in alveolar/arterial oxygen difference $\mathrm{P}(\mathrm{A}-\mathrm{a}) \mathrm{O}_{2}$ between dogs at equivalent levels of $\% \mathrm{O}_{2}$ sat. $\dot{Q}$ s/Q்t at full saturation ranged from 5.5 to 6.5 per cent and decreased exponentially with altered oxygen saturation to reach a fairly constant level of 0.5 per cent below 70 per cent oxygen saturation (Figure 5). It is of interest that two dogs at severe hypoxia had negative values for $\dot{Q} / \dot{Q} t$. Similarly the $\mathrm{P}(\mathrm{A}-\mathrm{a}) \mathrm{O}_{2}$ decreased exponentially but was fairly constant at $5 \mathrm{~mm} \mathrm{Hg}$ below 70 per cent oxygen saturation. The $\mathrm{P}(\mathrm{A}-\mathrm{a}) \mathrm{O}_{2}$ curve was shifted (hatched line) to the left around the point of inflection (80 to 90 percent oxygen saturation) compared with the curve for $\dot{Q} s / \dot{Q} t$ (solid line). One of the negative $\dot{Q} s / \dot{Q} t$ values was associated with a negative $\mathrm{P}(\mathrm{A}-\mathrm{a}) \mathrm{O}_{2}$. 


\section{Discussion}

Alveolar hypoxia constricts pulmonary arterial vessels and results in increased pulmonary vascular resistance in both the isolated lung and in intact animals. ${ }^{2,4.15,19}$ While the exact mediator of this response is not known, the possible mechanisms have recently been reviewed in detail. ${ }^{9.20}$ The increase in resistance is now thought to result from reduction in the calibre of small arteries of less than $0.2 \mathrm{~mm}$ diameter through active constriction 9.21 and is thought to be essentially a response to local change in alveolar $\mathrm{Po}_{2} .{ }^{22}$ However, the magnitude of the increase in resistance varies greatly between species ${ }^{12}$ and within the same species $^{6}$ for any given level of alveolar hypoxia. The results which we have found confirm the variability of the PVR response to hypoxia in the dog as compared with the published reports for the mean change $e^{3,6,13,14-17}$ and support the findings of Barer, ef al. ${ }^{7}$ in isolated lungs of cats where curvilinear but not significant relationships were found for PVR against arterial $\mathrm{Po}_{2}$.

Hypoxia resulted in a 43 per cent increase in the group mean Ppa and a 56 per cent increase in mean PVR, while cardiac output was virtually unchanged. This compares with the study of Sackner, et al. ${ }^{21}$ where equivalent levels of hypoxia resulted in a 60 per cent increase in PVR, and also that of Malik \& Kid's where PVR was increased by about 50 per cent. Despite the close similarity between our study and those quoted, significant differences exist. Our values for control $\dot{Q}$ were some two times higher and, further, did not change with hypoxia, whereas Malik \& Kidd ${ }^{\text {s }}$ found that $Q$ increased by some 30 per cent, but at a slower rate than the rise in Ppa.

This difference in the cardiac response is likely due to the use of the muscle relaxant pancuronium bromide in our study. This drug is known to have inotropic as well as chronotropic actions on the heart, resulting in a sustained elevation of cardiac output. The fact that we did not find any change in $\dot{Q}$ with hypoxis suggests that the cardiac response (increasing $Q$ with decreasing $\mathrm{P}_{\mathrm{A}_{\mathrm{O}_{2}}}$ ) which Malik \& Kidd's found may depend on the level of the resting or control $\dot{Q}$. Further, the cardiac response is higher in spontaneously breathing animals ${ }^{6}$. It is possible that the small degree of hypocapnia which we found during hypoxia, despite controlled ventilation, could have further attenuated the cardiac response. 's What is clear, however, is that the magnitude of the PVR response to hypoxia is little affected by these differences in cardiac output. In the case of the individual dog PVR responses, the curvilinear relationships we found against $\mathrm{Pa}_{\mathrm{O}_{2}}$ contrasts with the highly significant and reproduceable inverse linear correlations with arterial oxygen saturation. Thus we conclude that the PVR response to hypoxia is uniquely related to arterial oxygen saturation in individual animals, and that the slope of the response varies greatly from one animal to another. Further, we have shown that the slope of the PVR response can be predicted with a high degree of accuracy in individual animals from the slope of the $\mathrm{Ppa}$ response. At any given level of $\mathrm{PA}_{\mathrm{O}_{2}}$, the arterial oxygen saturation depends on a number of factors; haemoglobin and haematocrit levels, blood $\mathrm{pH}$ and temperature, alveolar dead space. shunt flow, venous admixture and matching of ventilation and perfusion. All of these could affect the PVR response to hypoxia directly or indirectly. We did not find any change in temperature or dead space/tidal volume ratio and, although the arterial $\mathrm{pH}$, haemoglobin and haematocrit values were increased above control these were not sufficient to appreciably alter oxygen saturation calculated from the Rossing and Cain equation $^{18}$ for dog blood. The most important factor determining arterial oxygen saturation is probably ventilation perfusion ratio. ${ }^{11}$

Increasing Ppa by itself reduces the relative topographical differences in pulmonary blood flow in the dog lung ${ }^{23}$ but this results in only a small improvement in gas exchange since $\mathrm{P}(\mathrm{A}-\mathrm{a})_{\mathrm{O}_{2}}$ is normally low. Recent studies have shown that local alveolar hypoxia results in redistribution of blood flow away from hypoxic areas, thus minimizing arterial oxygen desaturation ${ }^{24,25}$ and also that regional differences may exist in the ability of the pulmonary vessels to respond by constriction to hypoxia. ${ }^{26,27}$ It seems possible that similar differences may also exist between animals in the overall responsiveness of the pulmonary resistance vessels to alveolar hypoxia. Our findings tend to confirm this hypothesis and further suggest that the net gas exchange effect in terms of arterial oxygen saturation is unique to the individual. Clearly those animals having a low PVR response to hypoxia also have more marked arterial oxygen desaturation at equivalent levels of inspired and alveolar oxygen. In other words, high responders are able to maintain higher levels of arterial oxygen saturation.

A number of possible factors are known to alter the tone and calibre of lung resistance vessels in association with hypoxia. Release of bioactive 
amines such as histamine, serotonin, and catecholamines, ${ }^{28}$ adenosine, ${ }^{29}$ prostaglandins, ${ }^{30}$ as well as increased conversion of angiotensin I to angiotensin $11,{ }^{31}$ have been reported and individual rates of agonist release do occur. No single humoral mediator, however, has so far been clearly identified with the hypoxic response; nevertheless, some or all of the pulmonary vascular agonists quoted above probably at least modulate this response in vivo. ${ }^{32}$ The presence of erythrocytes within the pulmonary circulation has recently been shown to be essential for maintenance of normal vascular tone and responsiveness to stimulation by agonist, ${ }^{33}$ while platelets as a possible source of adenosine compounds, serotonin, and prostaglandins were not essential for the pressor response during hypoxia. While variations in the amount of mediator released in response to hypoxia is a distinct possibility, this would account only for difference in the magnitude of the response and does not explain the linearity of the PVR relationship with arterial oxygen saturation. The efficiency of active contraction in pulmonary vascular smooth muscle which results in the haemodynamic response also depends to a large extent on the physical properties of the vessel walls. Thickening of the media smooth muscle layer of pulmonary arterial vessels, such as occurs with chronic hypoxia, is an adaptive process to prolonged stimulation, and may result also in increased reactivity.

The haemodynamic effects of such adaptive structural changes have been described in detail for resistance vessels in hypertension ${ }^{34}$ in the systemic circulation and it seems probable that similar adaptations exist within the pulmonary circulation as well, even though the haemodynamic effects may differ. The relatively high compliance of the pulmonary arterial vessels would tend to maintain low perfusion pressures even in the presence of moderate vessel adaptations. However, such adaptations could result in significant differences in vascular reactivity due to variation in the total amount of smooth muscle membrane, with associated vaso-active agonist receptor sites. Induction of pulmonary hypertension with dextran infusion results in marked attenuation of the pulmonary vascular response to hypoxia in dogs, ${ }^{35}$ but we were unable to find any consistent relationship between the magnitude of the PVR response to hypoxia expressed as the slope against oxygen saturation or in the absolute rise in Ppa or PVR, with the pre-existing control Ppa or PVR. Nevertheless, there was a tendency for dogs with lower responses to have higher baseline perfusion pressures. Further studies are necessary to determine the exact role of pulmonary vessel structure in the variability of the PVR response to hypoxia.

\section{SUMMARY}

Anaesthetized and mechanically ventilated dogs were subjected to five minutes of alveolar hypoxia with $\mathrm{FI}_{\mathrm{O}_{2}}$ ranging from 0.08 to 0.20 while pulmonary artery pressure (Ppa), pulmonary wedge pressure (Pwp) and cardiac output (Q) were measured. Hypoxia increased $P$ pa in all dogs whereas Pwp and $\dot{Q}$ did not change significantly. Thus pulmonary vascular resistance (PVR) increased by a mean for all dogs of 56 per cent. There was great variation in the absolute increase in Ppa and PVR between animals and these were not statistically correlated with arterial $\mathrm{PO}_{2}$, but highly significant and reproduceable inverse relationships were found for Ppa and PVR against arterial oxygen per cent saturation. The slopes of these responses varied between dogs from -0.013 to -0.144 for PVR and from -0.038 to -0.561 for Ppa. The alveolar-arterial oxygen gradient and the pulmonary shunt fraction were reduced in a similar way with decreasing arterial oxygen per cent saturation, but dead space/tidal volume ratio remained unchanged. Thus the slope of PVR response to hypoxia against arterial oxygen per cent saturation is unique for individual animals. This may reflect functional and likely structural adaptations of the pulmonary vascular smooth muscle.

\section{RÉSUMÉ}

Des chiens anesthésiés et ventilés mécaniquement ont étè soumis à des épisodes d"hypoxie alvéolaire de cinq minutes en les exposant à des $\mathrm{Fl}_{\mathrm{O}_{2}}$ de 0,08 , de 0,11 , de 0,16 et de 0,2 ; la pression artérielle pulmonaire, la pression pulmonaire coincée (wedge) et le débit cardiaque étaient mesurés lors de ces épisodes.

L'hypoxie s'est traduite par une élévation de la pression de l'artère pulmonaire chez tous les chiens, alors que la pression pulmonaire coincée et le débit cardiaque n'ont pas changé de façon significative. On a observé une élévation de la résistance vasculaire pulmonaire chez tous les chiens (élévation moyenne de 56 pour cent). L'on a noté de grandes variations dans les augmentations de pression artérielle pulmonaire et de résistance vasculaire pulmonaire, variations sans rela- 
tion significative avec la $\mathrm{Pa}_{\mathrm{O}_{2}}$; une relation in" verse hautement significative et constante a cependant été trouvée entre la pression de l'artère pulmonaire et la résistance vasculaire pulmonaire et la saturation en oxygène du sang artériel.

Le gradient en oxygène alvéolo-artériel et le shunt diminuaient avec la désaturation en oxygène, mais le rapport espacemort/volume courant demeurait le même. Donc, la courbe représentant la modification de résistance vasculaire pulmonaire secondaire à l'hypoxie en rapport à la saturation artérielle en oxygène est unique chez un animal donné. Ceci peut représenter des adaptations fonctionnelles et possiblement structurales de la musculature vasculaire pulmonaire.

\section{ACKNOWLEDGEMENTS}

The authors gratefully acknowledge the assistance of the Department of Biostatistics and Epidemiology, McMaster University, for statistical analysis, and to Miss Joyce Brandsen for typing the manuscript.

\section{REFERENCES}

1. Plumier, P.L. La circulation pulmonaire chez Je chien. Arch. Internat. de Physiol. 1: 176-213 (1904).

2. Euler, V.S. von \& Liluestrand, G. Observations on the pulmonary arterial blood pressure in the cat. Acta Physiol. Scand. 12: 301-320 (1946).

3. LEwIS, B.M. \& GoRLIN, R. Effects of hypoxia on pulmonary circulation of the dog. Am. J. Physiol. 170: 574-587 (1952).

4. Llovo, T.C., JR. Effect of alveolar hypoxia on puimonary vascular resistance. J. Appl. Physiol. 19: 1086- 1094 (1964).

5. Stroud, R.C. \& ConN, H.L., JR. Pulmonary vascular effects of moderate and severe hypoxia in the dog. Am. J. Physiol. 179: 119-122 (1954).

6. TUCKeR, A. \& ReEves, J.T. Non-sustained pulmonary vasoconstriction during acute hypoxia in anaesthetized dogs. Am. J. Physiol. 228: 756-761 (1975).

7. Barer, G.R., Howard, P., \& SHaw, J.W. Stimulus-response curves for the pulmonary vascular bed to hypoxia and hypercapnia. J. Physiol. (Lond.) 21/: 139-155 (1970).

8. Fishman, A.P. Respiratory gases in the regulation of the pulmonary circulation. Physiol. Rev. 41 214-280 (1961).

9. Fishman, A.P. Hypoxia on the pulmonary circulation. How and where it acts. Circulation Res. 38: $221-231$ (1976).

10. Hauge, A. Hypoxia and pulmonary vascular resistance. The relative effects of pulmonary arterial and alveolar $\mathrm{PO}_{2}$. Acta Physiol. Scand. 76: 121-130 (1969).
11. West, J.B. Regional differences in gas exchange in the lung of erect man. J. Appl. Physio]. 17: 893-898 (1962).

12. Grover, R.F., Vogel, K.H., Averill, K.H., \& Blount, G.S., Jr. Pulmonary hypertension. Individual and species variability relative to vascular reactivity. Am. Heart J. 66: 1-3 (1963).

13. Berry, W.B., Mclaughlin, J.S., Clark, W.D., \& Morrow, A.G. The effects of acute hypoxia on pressure, flow and resistance in the pulmonary vascular bed. Surgery 58: 404-411 (1965).

14. Daly, I., Michel, C.C., Ramsay, D.J., \& WAaler, B.A. Conditions governing the pulmonary vascular response to ventilation hypoxia and hypoxaemia in the dog. J. Physiol. (Lond.) 196: 351-379 (1968).

I5. MaLIK, A.B. \& KIDD, S.L. Time course of pulmonary vascular response in dogs. Am. J. Physiol. 224: 1-6(1973).

16. Thilenius, D.G. \& Derenzo, C. Hypoxic pulmonary vasoconstriction in unanaesthetized dogs with constant arterial $\mathrm{PCO}_{2}$ and $\mathrm{pH}$. Clin. Sci. 37: $731-737$ (1969).

17. Thilenius, D.G. \& Derenzo, C, Eftects of acutely induced changes in arterial pH on pulmonary vascular resistance during normoxia and hypoxia in awake dogs. Clin. Sci. 42: 277-287 (1975).

18. Rossing, R.G. \& CAIN, S.M. A nomogram relating $\mathrm{PO}_{2}, \mathrm{pH}$, temperature, and haemoglobin saturation in the dog. J. Appl. Physiol. 2l: 195-201 (1966).

19. Viles, P.H. \& Shepherd, J.T. Relationship between $\mathrm{pH}, \mathrm{PO}_{2}$ and $\mathrm{PCO}_{2}$ on the pulmonary vascular bed of the cat. Am. J. Physiol. 215: 1170-1176 (1968).

20. BeRGofSKy, E.H. Mechanisms underlying vasomotor regulation of regional pulmonary blood flow in normal and diseased states. Am. J. Med. 57: 378-394 (1974).

21. Sackner, M.A., Will., D.H., \& DuBors, A.B. The site of pulmonary vasomotor activity during hypoxia or serotonin administration. J. Clin. Invest. 45: 112-121 (1966).

22. Grant, B.J.B., Davies, E.E., Jones, H.A., \& HugHES, J.M.B. Local regulation of pulmonary blood flow and ventilation perfusion ratios in the coati-mundi. J. Appl. Physiol. 40: 216-228 (1976).

23. West, J.B., Dollery, C.T., \& Naimark, A. Distribution of blood flow in isolated lung: relation to vascular and alveolar pressures. J. Appl. Physiol. 19: 713-724 (1964).

24. Arborelius, M., JR., LiLja, B. \& Zauner, C.W The relative effect of hypoxia and gravity on pulmonary blood flow. Respiration 31: 369-380 (1974).

25. Kato, M. \& Staub, N.C. Response of small pulmonary arteries to unilobar hypoxia and hypercapnia. Circulation Res. 19 : 426-440 (1966).

26. Hales, C.A., Ahluwalia, B., \& Kazemi, H. Strength of pulmonary vascular response to regional hypoxia. J. Appl. Physiol. 38: 1083-1087 (1975).

27. Maloney, J.E., Alcorn, D., Cannata, J. WAlKer, A., \& RutchiE, B.C. Regional vascular response to hypoxia in the lungs of anaesthetized sheep. Austral. J. Exp. Biol. Med. Sci. 52: 80I-812 (1974). 
28. Hauge, A. \& Melmon, K.L. Role of histamine in hypoxic pulmonary hypertension in the rat. II. Depletion of histamine, serotonin and catecholamines. Circulation Res. 22: 371-392 (1968).

29. Mentzer, R.M., Jr., Rubio, R., \& Berne, R.M. Release of adenosine by hypoxic canine lung tissue and its possible role in the pulmonary circulation. Am. J. Physiol, 229: 1625-1631 (1975).

30. Kadowitz, P.J., JoIner, P.D., \& Hyman, A.L. Physiological and pharmacological roles of prostaglandins. Aan. Rev. Pharmacol, 15: 285-306 (1975).

31. Berkov, S. Hypoxic pulmonary vasoconstriction in the rat. The necessary role of angiotensin II. Circulation Res. 35: 256-261 (1974).
32. Tucker, A., Hoffman, E. A., \& Weir, E. K. Histamine receptor antagonism does not inhibit hypoxic pulmonary vasoconstriction in dogs. Chest $7 /: 261-262$ (1977).

33. McMuktry, I.F., Hookway, B.W., \& Roos, S. Red blood cells play a crucial role in maintaining vascular reactivity to hypoxia in isolated rat lungs. Chest 7/: 253-255 (1977).

34. Folkow, B. Haemodynamic consequences of adaptive stnactural changes of the resistance vessels in hypertension. Clin. Sci. 41: 1-12 (1971).

35. Benumof, J.L. \& Wahrenbrock, E.A. Blunted hypoxic pulmonary vasoconstriction by increased lung vascular pressures. J. Appl. Physiol. 38: 846-850(1975). 